\section{Multidisciplinary SCIENTIFIC JOURNAL OF MARITIME RESEARCH}

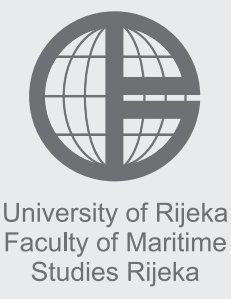

Multidisciplinarni znanstveni časopis POMORSTVO

https://doi.org/10.31217/p.32.2.10

\title{
Assessment of the Performance Status of a Wharf
}

\author{
Pereowei Garrick Ombor, Thaddeus C. Nwaoha \\ Marine Engineering Department, Federal University of Petroleum Resources, Nigeria, e-mail: ombor.pereowei@fupre.edu.ng; \\ nwaoha.thaddeus@fupre.edu.ng
}

\begin{abstract}
This paper suggests Fuzzy-logic-rule base method to assess the performance status of a wharf in order to classify it. The method proposed is predicated upon its ability to analyse processes and operations based on subjective judgement with little or no statistical data available. The study also shows that fuzzy-logic rule base is a veritable tool to qualitatively and quantitatively assess the status of a wharf offering ferry service. Using the model developed in this study, the performance status of Yenagoa wharf has been determined to be orange, having a (WPS) overall of 4.8. The status of the wharf has been in good agreement with the perception of stakeholders that the Yenagoa wharf needs restructuring to curb the frequent crisis occurring among stakeholders. The model also indicated those areas of the wharf's operations needing attention. The study indicates that even though major components that determine the quality and profitability of the wharf's ferry service are high in value, the overall status of the wharf may not be necessarily high. As such, the study method can be used to control the growing ill-feeling between boat operators and passengers while harmonizing all stakeholders (operators, passengers, and regulators etc) to work together to improve the status of the wharf.
\end{abstract}

\section{ARTICLE INFO}

Original scientific paper

Received 12 November 2018

Accepted 5 December 2018

\section{Key words:}

Fuzzy-logic-rule base

Wharf

Passengers

Boat operators

Ferry

Status

Service quality

Internal rate of return

\section{Introduction}

"We do not have any alternative means to reach our destination" was a statement made by an unsatisfied passenger who boarded a ferry boat at a ferry boat departure centre (wharf) that provides commercial ferry services. This statement speaks volume about the wellbeing of the ferry services offered at that wharf. This insightful statement can be demystified by taking a critical look into the return on investment by the wharf operators and quality of service offered to passengers.

Commercial ferry services in most riverine communities of some developing countries are offered by wharf operators who own boats as well as register other boat owners to use the wharf to ply certain routes. The activities of the boat operators are supervised by the wharf operators who are in turn regulated by the Inland Waterways Authority. Owing to the high initial capital investment and operational cost requirement as well as high risk associated with the boat operations, the boat operators are overly concerned about their return on investment. On the other hand, passengers feel unfair charges are levelled against them for the quality of service they receive. Moreover, owning to the inaccessibility by road, passengers are faced with a situation where there are no other means to reach their destination.

The growing ill-feeling between the two parties demands a close examination on the factors fuelling this sentiment. Statistical results from questionnaires administered to both the boat operators, passengers, academia and regulators during this research indicates two measurement parameters are to be considered to assess the state of the ferry service. They are:

1. Parameter that measures the return on revenues made by the operators.

2. Parameter that Measures the Quality of the Ferry Service.

Service quality has been identified by [1] as the main single factor influencing service business or organizational unit performance. The relationship existing between service quality, customers' satisfaction and investors profit or returns has been studied by [1-4]. The study identified service quality as an antecedent of the customer's satisfaction, the customer's satisfaction directly affecting purchase intention and the customer's satisfaction as an antecedent of profitability. It was revealed that significant impact on re- 
turns on investment was found to be created by the customers' satisfaction on the service quality factors. However, it should be noted that in situations where a business unit has monopoly on the market and customers have no alternative service providers, customer's satisfaction plays a less significant role in determining the returns of investors. Under such situations, the service quality will have a significant impact on the returns made by the business unit.

A singular parameter that captures the impacts of the boat operators' return on investment and the service quality will be ideal to establish the position of the operators, passengers and other stakeholders as it concerns how well the ferry service activities are carried out. In other words, this singular parameter will define the performance status of the wharf.

Status according to [5] is the situation of something at a particular time, while [6] defines it as the state or condition of affairs. The status of the ferry service industry thus means the state, condition or situation of affairs in the ferry service operations at a particular time. The status of the ferry business activity holistically considers the influence and impact the ferry business activities have on all the stakeholders, especially the passengers and the boat operators.

A parameter that measures the status of the wharf should be more encompassing than either the parameters that measures the service quality or the operators' returns on investment over a time frame. This paper has introduced the application of fuzzy-logic-based method to precisely define the performance status of a wharf at any given time.

\section{Methodology}

Fuzzy logic was invented by Zadeh in 1965, to solve uncertainty problems [7]. It solves uncertainty problems using linguistic terms to represent human reasoning. There are various techniques of fuzzy logic such as discrete and continuous fuzzy sets, and fuzzy rule base that can be used in uncertainty treatments in the maritime industry [8]. The mechanism of the fuzzy rule base can be employed in the capturing of subjective information in the assessment of the performance status of a wharf because of the flexibility in solving uncertainty problems. Fuzzy rule base uses IF-THEN rule approach. A fuzzy IF-THEN rule is a knowledge representation scheme for capturing human knowledge that is imprecise by nature $[9,10]$. This is achieved by using linguistic variables to describe conditions that can be satisfied to a degree in the "IF" part of the fuzzy rules [9]. It represents degrees of membership of members in sets.

The fuzzy-logic-based method, used in this study, follows closely the one often used in fuzzy control and fuzzy safety modelling systems [11]. The method used to assess the state of the ferry service industry involves the following:

- Determination and definition of fuzzy input and output variables and set definitions from knowledge and opinions of experts and stakeholders
- Development of fuzzy rule base

- Fuzzy inference process

- Determination of the output crisp value of the overall state of the ferry industry.

\subsection{Determination and Definition of Fuzzy Input Variables and Set Definitions}

The performance status of a wharf at any interval can be defined by two core attributes or parameters of the service, namely; the service quality and the Operators' Internal Rate of Return on Investment (IRR). The use of both attributes to assess the state of the wharf is justified because they capture the perception of operators, passengers and other stakeholders about the operations of the wharf over a period of time. They also assist in establishing if the ferry service activities give the right value for the operators' investment and customers' patronage.

The IRR is quantitative and can be precisely evaluated and measured with little or no ambiguities. On the other hand, service quality as an attribute is qualitative and associated with uncertainties when measured. The foregoing provides a basis for the use of fuzzy logic system to assess the state of the ferry service industry. The fuzzy logic system has been shown to handle both qualitative and quantitative data in a consistent manner. It resolves problems of this nature by using measurable values derived from linguistic variables (stated in natural language forms) which can assess the performance status of the wharf.

Fuzzy linguistic variables can be used to represent the conditions of the service quality and IRR attributes as well as develop the fuzzy membership functions. The fuzzy linguistic variables take words as their values and these values are generally characterized by fuzzy sets [11] defined in the input-output space containing the linguistic variables [12-13]. The fuzzy sets are the criteria used to measure the conditions of the attributes of the wharf's service. Owing to the relevance of service quality and operators IRR in determining the status of the wharf, they are taken as the input parameters to the fuzzy logic system used.

\subsubsection{Fuzzy Service Quality Key Indicator (SQKI) Set Definition}

The factors that influence service quality are numerous. To properly define the service quality as an input variable to the fuzzy logic system, a means to aggregate these factors into categories of dominant factors is highly recommended [14]. An aggregation method involving a combination of Kendall's Coefficient of Concordance [15] and the 5-point Likert Scale [16] has been employed in the ranking and weighing type Delphi technique $[17,18,19]$ to categorize, define the rank as well as the weight of the factors influencing the service quality.

Experts have been chosen among passengers, boat operators, regulators and the academia. Following the concepts of analogical reasoning [20], conceptual proximity [21] and structural similarities [22], three categories of 
dominant factors influencing ferry service quality have been developed. In each category, the fuzzy linguistic variables and fuzzy sets have been developed for each dominant factor. Tables 1, 2 and 3 show the criteria used to rate the value of stakeholders' opinions about the dominant factors that influence the wharf's service quality.

The aggregation of all the dominant factors in a category yields the Service Quality Key Indicator (SQKI) for that category. The SQKI gives a qualitative and quantitative view about the impact of a block (category) of dominant factors on the overall level of the ferry service quality. As such, it is appropriate to regard the SQKI as the service quality input parameter for the fuzzy logic system. Three SQKI categories have been developed in this study. They are:

- Design/Operations-SQKI which is the boat design and operations related SQKI

- Care/Safety-SQKI which is the care of passengers, safety and security related SQKI

- Environment-SQKI which is the environment related SQKI
The qualitative and quantitative value of service quality can be defined according to how appealing the service on these three categorical areas pertinent to the wharf's ferry operation. The crisp value of the service quality parameter appropriately represented by the numerical value of the SQKI for any category j, of the dominant factors that can be determined from the following dominant factors aggregation relation [23]:

$$
(S Q K I)_{j}=\sum_{1}^{n} \mathbb{Z}\left[(D F W) \Sigma_{i} \times(S Q O)_{i}\right]
$$

$(S Q O)_{i}=$ The scaled value of stakeholders' opinion about a dominant factor $i$ which influences the wharf's service quality. In other words, it is a value assigned to a linguistic variable used by a stakeholder to express an opinion about a dominant factor $i$ which represents a component of the wharf's ferry operation. The service quality opinions (SQO) values for the various categories are shown in Tables 1, 2 and 3.

Table 1 Criteria for Rating the SQO Description on Boat Design/Operations

\begin{tabular}{|c|c|c|c|}
\hline \multicolumn{4}{|r|}{ Design and Operation Category Factors (DO Category) } \\
\hline $\begin{array}{c}\text { Dominant } \\
\text { Factors }\end{array}$ & Scale & $\begin{array}{c}\text { Stakeholders' } \\
\text { Opinion }\end{array}$ & Description \\
\hline $\begin{array}{l}\text { (a) Cost of } \\
\text { Transport } \\
\text { Fare }\end{array}$ & $\begin{array}{c}0 \\
2.5 \\
5 \\
7.5 \\
10\end{array}$ & $\begin{array}{l}\text { Too High } \\
\text { High } \\
\text { Moderate } \\
\text { Low } \\
\text { Very Low }\end{array}$ & $\begin{array}{l}\text { - The transport fare is excessive and way too high above industry standard } \\
\text { - The transport fare is slightly beyond industry standard } \\
\text { - The transport fare is generally within industry standard acceptable } \\
\text { - The transport fare is slightly below industry standard } \\
\text { - The transport fare is much below industry standard }\end{array}$ \\
\hline $\begin{array}{l}\text { (c) Speed of } \\
\text { Boat }\end{array}$ & $\begin{array}{l}0 \\
2.5 \\
5 \\
7.5 \\
10\end{array}$ & $\begin{array}{l}\text { Very Slow } \\
\text { Slow } \\
\text { Moderate } \\
\text { High } \\
\text { Very High }\end{array}$ & $\begin{array}{l}\text { - The boat speed is below } 12 \text { knots for routes without regulation. } 10 \% \text { of the speed } \\
\text { regulation limit for routes with speed regulation. } \\
\text { - The boat speed is between } 12-16 \text { knots for routes without regulation. } 20-30 \% \text { of speed } \\
\text { regulation limit for routes with speed regulation. } \\
\text { - The boat speed is about } 23 \text { knots for routes without regulation. } 40-60 \% \text { of speed regulation } \\
\text { limit for routes with speed regulation. } \\
\text { - The boat speed is between } 23-30 \text { knots for routes without regulation. } 70-80 \% \text { of speed } \\
\text { regulation limit for routes with speed regulation. } \\
\text { - The boat speed is above } 30 \text { knots for routes without regulation. } 90-100 \% \text { of speed regulation } \\
\text { limit for routes with speed regulation. }\end{array}$ \\
\hline $\begin{array}{l}\text { (d) Boat } \\
\text { Loaded } \\
\text { Condition }\end{array}$ & $\begin{array}{l}0 \\
5.5 \\
10\end{array}$ & $\begin{array}{l}\text { Overloaded } \\
\text { Slightly } \\
\text { Overloaded } \\
\text { or Underloaded } \\
\text { Optimally Loaded }\end{array}$ & $\begin{array}{l}\text { - Waterline is near the top edge of the boat depending on the cargo carrying capacity of the } \\
\text { boat } \\
\text { - Waterline is slightly above or below the design waterline mark. It depends on the boat } \\
\text { hull capacity } \\
\text { - Waterline is at the design waterline mark }\end{array}$ \\
\hline
\end{tabular}


Table 2 Criteria for Rating the SQO on the Care of Passengers, Safety and Security

\begin{tabular}{|c|c|c|c|}
\hline \multicolumn{4}{|r|}{ Care, Safety and Security Category Factors (CSS Category) } \\
\hline $\begin{array}{l}\text { Dominant } \\
\text { Factors }\end{array}$ & Scale & \begin{tabular}{|c|}
$\begin{array}{c}\text { Stakeholder-s' } \\
\text { Opinion }\end{array}$ \\
\end{tabular} & Description \\
\hline $\begin{array}{l}\text { (f) } \\
\text { Competence } \\
\text { and } \\
\text { Experience } \\
\text { of Driver }\end{array}$ & $\begin{array}{c}0 \\
2.5 \\
5 \\
7.5 \\
10\end{array}$ & $\begin{array}{l}\text { Very Low } \\
\text { Low } \\
\text { Moderate } \\
\text { High } \\
\text { Very High } \\
\end{array}$ & $\begin{array}{l}\text { - Operator is a trainee or has no experience of the route or boat operation } \\
\text { - Operator is recently trained or has very little experience of the route or boat operation. } \\
\text { - Operator has }<2 \text { years of experience of the route or boat operation and has built some competence } \\
\text { - Operator is competent and has several years of experience of the route } \\
\text { - Operator has distinctive competence and has many years of experience of the route }\end{array}$ \\
\hline $\begin{array}{l}\text { (g) Policies } \\
\text { and } \\
\text { Regulations }\end{array}$ & $\begin{array}{c}0 \\
2.5 \\
5 \\
7.5 \\
10\end{array}$ & $\begin{array}{l}\text { Very Bad } \\
\text { Bad } \\
\text { Moderate } \\
\text { Good } \\
\text { Very Good }\end{array}$ & $\begin{array}{l}\text { - Stakeholders view policies and regulations are highly against the interest of the industry } \\
\text { - Stakeholders view policies and regulations are unfavourable to the industry } \\
\text { - Stakeholders view policies and regulations are fair and for the good of the industry } \\
\text { - Stakeholders view policies and regulations are favourable to the industry } \\
\text { - Stakeholders view policies and regulations are very favourable to the industry }\end{array}$ \\
\hline $\begin{array}{l}\text { (h) } \\
\text { Availability/ } \\
\text { Quality of } \\
\text { Life Jacket }\end{array}$ & $\begin{array}{l}0 \\
2.5 \\
5.5 \\
10\end{array}$ & $\begin{array}{l}\text { Very Poor } \\
\text { Poor } \\
\text { Moderate } \\
\text { High }\end{array}$ & $\begin{array}{l}\text { - No life jacket are provided to passengers } \\
\text { - Damaged and outdated life jackets are provided to some or all the passengers } \\
\text { - Good quality life jackets are provided to some or all the passengers } \\
\text { - Very good quality life jackets are provided to all passengers }\end{array}$ \\
\hline $\begin{array}{l}\text { (i) } \\
\text { Availability } \\
\text { and } \\
\text { Quality of } \\
\text { Protection } \\
\text { against } \\
\text { Weather }\end{array}$ & $\begin{array}{l}0 \\
2.5 \\
5.5 \\
10\end{array}$ & $\begin{array}{l}\text { Very Poor } \\
\text { Poor } \\
\text { Moderate } \\
\text { High }\end{array}$ & $\begin{array}{l}\text { - No protection against harsh weather } \\
\text { - Tarpaulin is used to cover passengers when such a harsh weather condition arises } \\
\text { - Boat has in-built roof but no side protection against harsh prevailing weather condition } \\
\text { - Boat has in-built roof and side protection against harsh prevailing weather }\end{array}$ \\
\hline $\begin{array}{l}\text { (j) Attitude } \\
\text { of Boat } \\
\text { Operator }\end{array}$ & $\begin{array}{c}0 \\
2.5 \\
5 \\
7.5 \\
10\end{array}$ & $\begin{array}{l}\text { Very poor } \\
\text { Poor } \\
\text { Moderate } \\
\text { Good } \\
\text { Very Good }\end{array}$ & $\begin{array}{l}\text { - Operator is very rude and nonchallant to passengers' complaints. } \\
\text { - Operator is not friendly and cares less about passengers' complaints. } \\
\text { - Operator is reasonably friendly and sometimes listens to passengers' complaints. } \\
\text { - Operator is friendly and listens to passengers' complaints but makes little effort to solve them } \\
\text { - Operator is very friendly, listens to passengers' complaints and makes practical effort to help }\end{array}$ \\
\hline
\end{tabular}

Table 3 Criteria for Rating the SQO on Environmental Factors

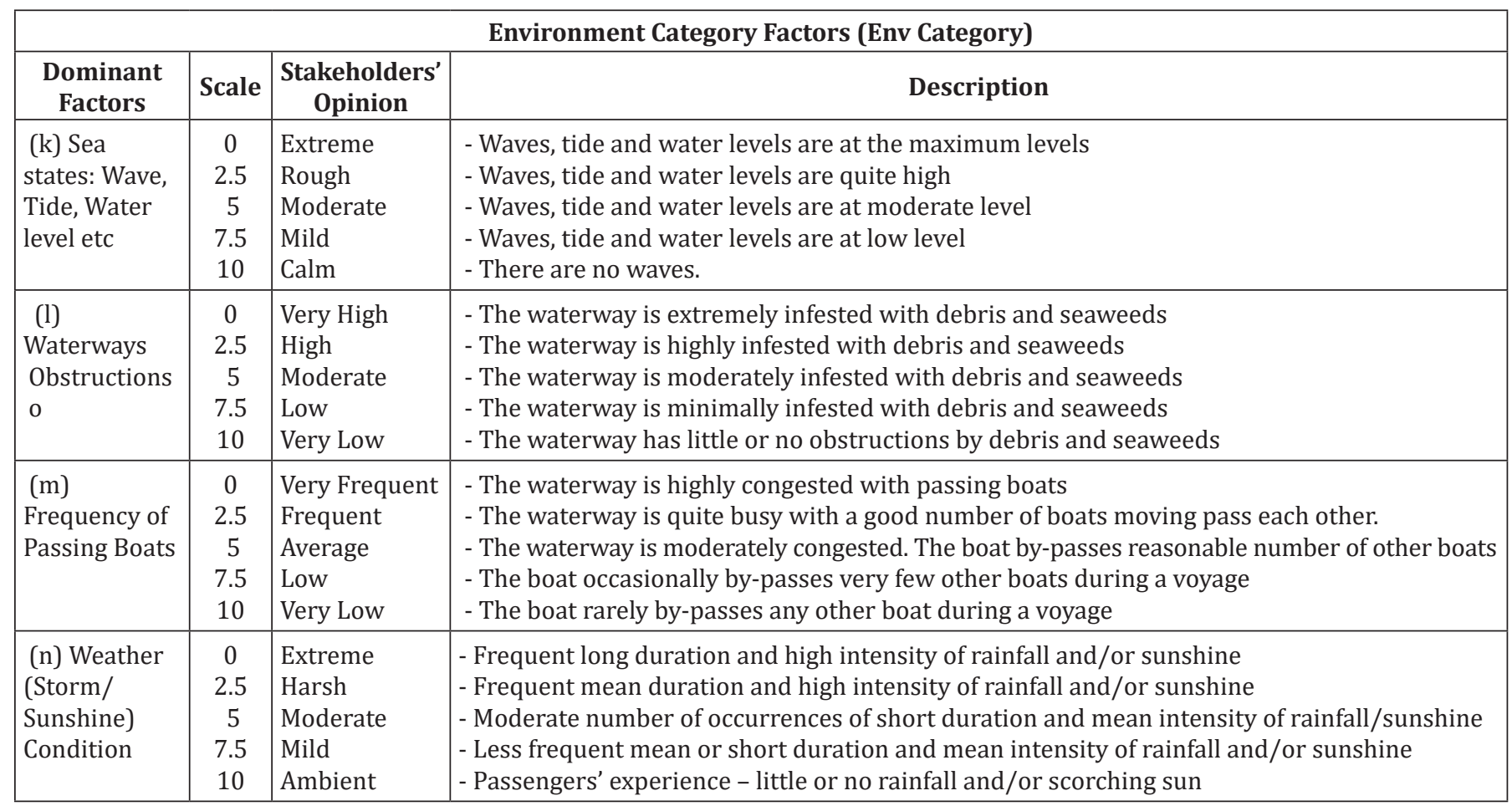


Table 4 Rank and Weight of Narrowed Down Consolidated List of Consensus Factors

\begin{tabular}{|c|c|c|c|c|c|c|c|c|}
\hline \multicolumn{3}{|c|}{ Category A: DO Factors } & \multicolumn{3}{|c|}{ Category B: CSS Factors } & \multicolumn{3}{|c|}{ Category C: ENV Factors } \\
\hline Dominant Factor & Scale & Weight & Factor & Scale & Weight & Factor & Scale & Weight \\
\hline $\begin{array}{l}\text { a) Cost of Transport } \\
\text { Fare }\end{array}$ & 1 & 0.30 & $\begin{array}{l}\text { f)Competence } \\
\text { \&Experience of Driver }\end{array}$ & 1 & 0.35 & $\begin{array}{l}\text { k) Sea states: waves, tide, } \\
\text { water level etc }\end{array}$ & 1 & 0.33 \\
\hline $\begin{array}{l}\text { b) Engine and Hull } \\
\text { Condition }\end{array}$ & 2 & 0.24 & g) Policies and Regulations & 2 & 0.27 & $\begin{array}{l}\text { l) Obstructions on } \\
\text { waterways e.g. presence of } \\
\text { debris, seaweeds, shallow } \\
\text { areas etc }\end{array}$ & 2 & 0.31 \\
\hline $\begin{array}{l}\text { d) Loaded Condition } \\
\text { of the Boat }\end{array}$ & 4 & 0.17 & $\begin{array}{l}\text { i) Availability and Quality } \\
\text { of protection against Storm } \\
\text { and Sunshine }\end{array}$ & 4 & 0.1 & $\begin{array}{l}\text { n) Weather (Storm/ } \\
\text { Sunshine) Condition }\end{array}$ & 4 & 0.17 \\
\hline $\begin{array}{l}\text { e) Time Spent at } \\
\text { Boarding Lounge }\end{array}$ & 5 & 0.11 & $\begin{array}{l}\text { j) Attitude of Boat } \\
\text { Operator }\end{array}$ & 5 & 0.07 & & & \\
\hline
\end{tabular}

Table 5 Service Quality Set Definition for all Categories of Dominant Factors

\begin{tabular}{|c|c|l|}
\hline Scale & Fuzzy SQKI Set & \multicolumn{1}{c|}{ Description } \\
\hline 0 & Very Low & Service quality expectations are not met and service quality is rated very poor \\
\hline 2.5 & Low & Satisfies few of the service quality expectations and service quality is rated poor \\
\hline 5 & Moderate & Satisfies some of the service quality expectations, the service is rated on an average \\
\hline 7.5 & High & Service quality is satisfactory and rated high \\
\hline 10 & Very High & Service quality very satisfactory and rated very high \\
\hline
\end{tabular}

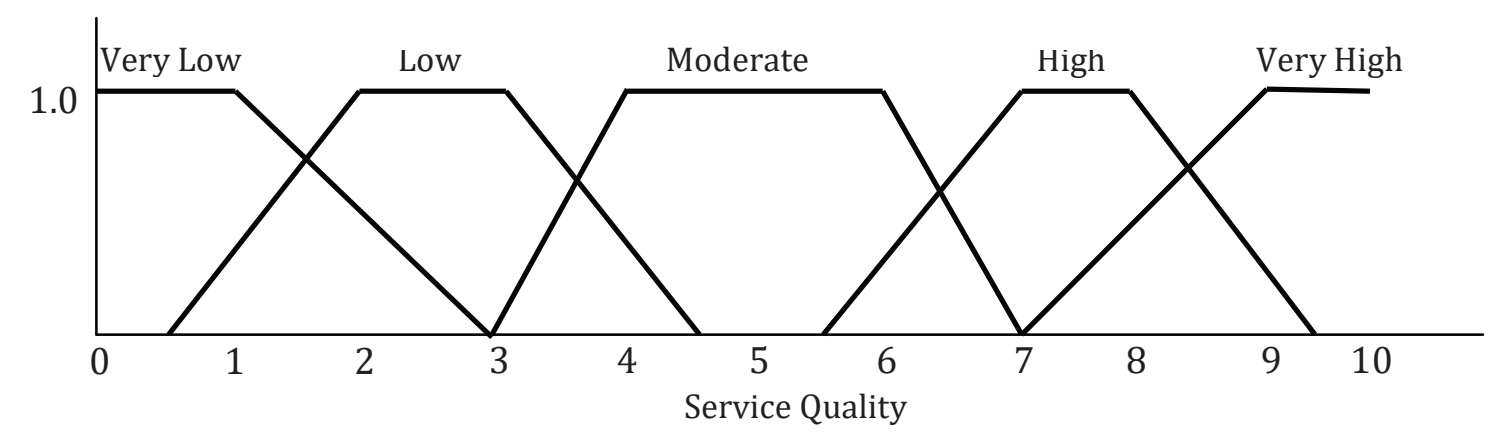

Figure 1 Fuzzy SQKI Set Definition

$(D F W)_{i}=$ Importance dominant factor weight $i$ in category j. The ranks and importance weights of each dominant factor in the category derived from Analytical Hierarchy Processing (AHP) analysis in this study is shown in Table 4.

Table 5 shows criteria for the SQKI set definition. The fuzzy SQKI set definition derived from a consensus opinion is shown in Fig. 1.

It can be seen from Table 5 that five levels of fuzzy linguistic variables have been used for the SQKI expressions. The inclusiveness of the variables makes it realistic to represent SQKI expressions that overlap between any two levels.
The ranks and importance weights (Iw) of each SQKI category derived from AHP analysis in this study is shown in Table 6.

Table 6 Weight of SQKI Category

\begin{tabular}{|l|c|}
\hline \multicolumn{1}{|c|}{ Category } & Weight \\
\hline DO Related Category & 0.4 \\
\hline CSS Related Category & 0.4 \\
\hline ENV Related Category & 0.2 \\
\hline
\end{tabular}


Table 7 Internal Rate of Return (IRR)

\begin{tabular}{|c|c|l|c|}
\hline Scale & IRR & \multicolumn{1}{|c|}{ Description (General interpretation) } & Average IRR \\
\hline 0 & Very Low & Negative return on investment is unlikely but possible & $<10 \%$ \\
\hline 2.5 & Low & Operators are likely to make minimal returns on investment & $10 \%-20 \%$ \\
\hline 5 & Moderate & Average Return on investment & $30 \%-40 \%$ \\
\hline 7.5 & High & High return on investment is achieved by the operator & $50 \%-70 \%$ \\
\hline 10 & Very High & Operators make excessive returns on investment & $>80 \%$ \\
\hline
\end{tabular}

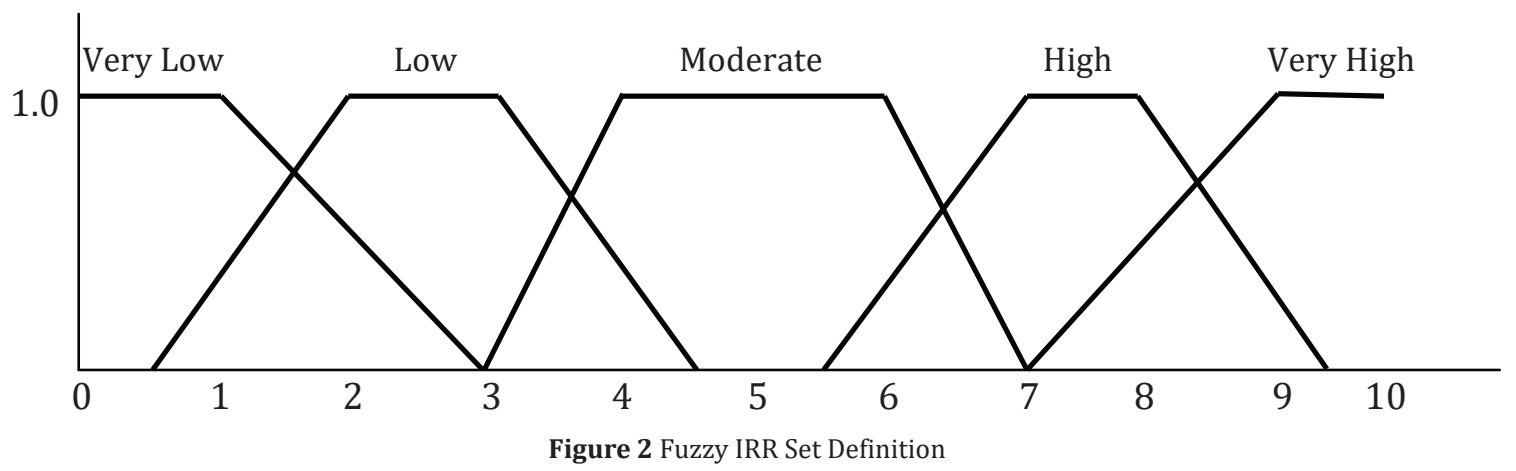

\subsubsection{Fuzzy Internal Rate of Return (IRR) Set Definition}

The IRR attribute (parameter) is the average annual return on the cash investment up through the point at which the IRR is measured for the wharf. The IRR reflects a sufficient risk-adjusted return on the cash investment given the nature of investment in the ferry service industry. The IRR shows just how high inflation rates or risk probabilities have to rise in order to eliminate the present value of an investment.

The fuzzy IRR variables describe the returns on investment expected from a particular mode of operation of the boat over a given period of the ferry service time. The productive life span of speed boats is ranged from 7 to 10 years. Each mode of the boat operation has a unique effect on the perception of the service quality at the wharf.

Table 7 describes the range of values of the internal rate of returns on investment and describes the fuzzy set for IRR. Linguistic variables such as very low, low, moderate, high and very high are used to describe IRR attribute of the wharf. Fig. 2 shows the fuzzy IRR set definition in the form a trapezoidal membership function.

\subsection{Determination and Definition of Fuzzy Output Variables and Set Definitions}

The goal of the output space in the rule base is to qualify and quantify the performance status of the wharf. The determination of the value of the wharf's performance status parameter (WPS) requires sound human expert judgement and knowledge which cannot be quantified without uncertainties. As such, it requires the establishment of fuzzy WPS linguistic variables and membership functions to represent the status of the wharf at a given interval.

The fuzzy WPS linguistic output variables have been developed based on fuzzy set theory during the Delphi study conducted by the researchers. Knowledge (expressed in linguistic form) acquired from experts in the ferry industry. The results of the analysis of collected ferry

Table 8 Performance Status of a Wharf

\begin{tabular}{|c|c|l|}
\hline Scale & $\begin{array}{c}\text { WPS } \\
\text { Variables }\end{array}$ & \multicolumn{1}{c|}{ Description (General Interpretation) } \\
\hline 1 & Red & $\begin{array}{l}\text { The wharf is off-track and has failed. Either stakeholders are not satisfied with the quality of services } \\
\text { offered at the wharf or operators return on investment is not acceptable. There is visible distraught between } \\
\text { operators and passengers. The wharf's operations need to be totally overhauled. }\end{array}$ \\
\hline 4 & Orange & $\begin{array}{l}\text { The operations at the wharf have major issues that need urgent attention to prevent the wharf from failing } \\
\text { or going off-track. Stakeholders are generally complaining about the ferry operations at the wharf. There is a } \\
\text { measure of distraught between the operators and the passengers. }\end{array}$ \\
\hline 7 & Yellow & $\begin{array}{l}\text { The wharf has some issues concerning its operations that need some attention. There is potential for some of } \\
\text { the stakeholders to be sentimental and start complaining about the wharf's ferry operations. }\end{array}$ \\
\hline 10 & Green & $\begin{array}{l}\text { The stakeholders are very satisfied with the ferry service activities at the wharf. Risks, operational, financial } \\
\text { and other issues have been identified and are under control. Impact of risk and issues is minimal. }\end{array}$ \\
\hline
\end{tabular}




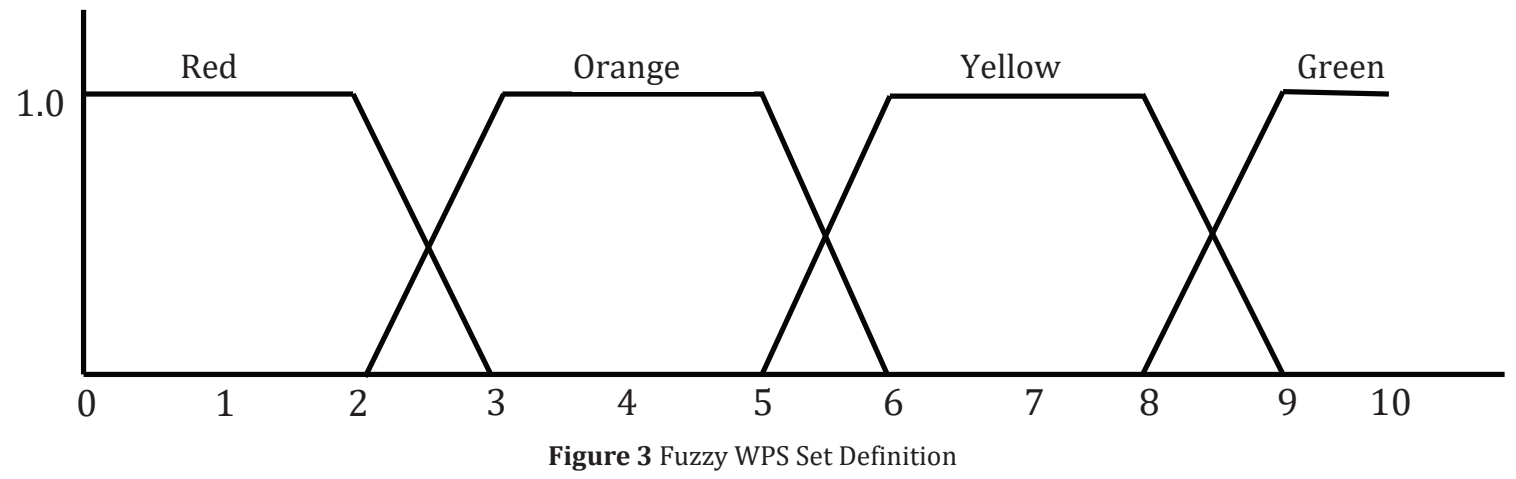

business data, expert judgement, concept mapping and in-depth literature search have been used in developing the fuzzy WPS linguistic output variables. To qualify the status of the wharf, four levels of linguistic variables in natural language form for the WPS expressions have been agreed upon by the participants during the Delphi study. These levels are Red, Orange, Yellow and Green as shown in Table 8. Fig. 3 shows the membership functions that describe the status of a wharf. As can be seen in Fig. 3, four levels of linguistic variables have been used for the WPS expressions.

\subsection{Development of Fuzzy Rule Base}

The fuzzy rule base is the central component of the model. It receives and processes all input variables into the fuzzy logic system and gives out a raw output values that must be refined to yield a crisp output value of the fuzzy logic system. The fuzzy rule base used in this paper consists of a set of fuzzy input and output described as antecedent and consequent respectively [23]. Fig 4 has been used to show the antecedent part of fuzzy rule base and the consequent part.

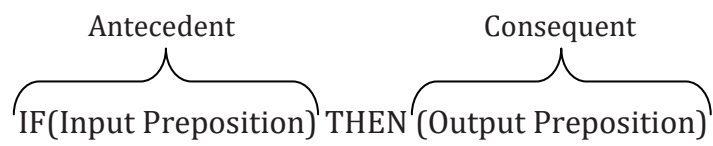

Figure 4 Structures / Composition of IF-THEN Fuzzy Rules [23]

The input and output prepositions are basically fuzzy linguistic variables describing the attributes of the ferry service industry. The IF-THEN rules provide a means to consider all possibilities of human logical reasoning outcomes for various sets of combination of the values of the antecedent in a system, process or events with uncertainty and imprecision. Relevant information about the status of the ferry service industry based on expert opinions and judgement expressed in natural language can thus be naturally abstracted. Fuzzy rules are developed in such a way that the fuzzy antecedents do not precisely match the inputs. Only those rules that have some relationship with the inputs will be activated to contribute to defining the status of a wharf. The degree of activation is related to how much the antecedents matches the input parameters. This imprecise matching provides a leeway to interpolate between possible input parameter values thereby minimizing the number of rules needed to define the inputoutput relation.

The fuzzy rules effectively combine the qualitative SQKI and the quantitative IRR parameters to define the status of the wharf. The database used to aid the combination of antecedents and consequents in the fuzzy rule base of this model has been developed from engineering knowledge, expert judgement, financial records of boat operators, metocean data, standards and regulations from regulatory bodies etc.

For fuzzy rules to be applicable, it should be complete (i.e. at any point in the input space there is at least one rule that is activated and the membership value of the IF part of the rule at this point is non zero), consistent (i.e. all rules with the same IF part must have the identical THEN part) and continuous (i.e. there should be neighbouring rules whose THEN part fuzzy sets have empty intersections [7]. Twenty five (25) fuzzy rules have been developed and checked for completeness, consistency and continuity in this study as shown below.

- Rule \#1: IF the IRR is very low AND SQKI is very low THEN the WPS is red

- Rule \#2: IF the IRR is very low AND SQKI is low THEN the WPS is red

- Rule \#3: IF the IRR is very low AND SQKI is moderate THEN the WPS is red

- Rule \#4: IF the IRR is very low AND SQKI is high THEN the WPS is orange

- Rule \#5: IF the IRR is very low AND SQKI is very high THEN the WPS is orange

- Rule \#6: IF the IRR is low AND SQKI is very low THEN the WPS is red

- Rule \#7: IF the IRR is low AND SQKI is low THEN the WPS is red

- Rule \#8: IF the IRR is low AND SQKI is moderate THEN the WPS is orange

- Rule \#9: IF the IRR is low AND SQKI is high THEN the WPS is orange

- Rule \#10: IF the IRR is low AND SQKI is very high THEN the WPS is orange 
- Rule \#11: IF the IRR is moderate AND SQKI is very low THEN the WPS is red

- Rule \#12: IF the IRR is moderate AND SQKI is low THEN the WPS is red

- Rule \#13: IF the IRR is moderate AND SQKI is moderate THEN the WPS is orange

- Rule \#14: IF the IRR is moderate AND SQKI is high THEN the WPS is yellow

- Rule \#15: IF the IRR is moderate AND SQKI is very high THEN the WPS is yellow

- Rule \#16: IF the IRR is high AND SQKI is very low THEN the WPS is red

- Rule \#17: IF the IRR is high AND SQKI is low THEN the WPS is orange

- Rule \#18: IF the IRR is high AND SQKI is moderate THEN the WPS is yellow

- Rule \#19: IF the IRR is high AND SQKI is high THEN the WPS is green

- Rule \#20: IF the IRR is very high AND SQKI is very high THEN the WPS is green

- Rule \#21: IF the IRR is very high AND SQKI is very low THEN the WPS is red

- Rule \#22: IF the IRR is very high AND SQKI is low THEN the WPS is red

- Rule \#23: IF the IRR is very high AND SQKI is moderate THEN the WPS is yellow

- Rule \#24: IF the IRR is very high AND SQKI is high THEN the WPS is green

- Rule \#25: IF the IRR is very high AND SQKI is very high THEN the WPS is green

\subsection{Fuzzy Inference Process}

The inference process for the relationship between the input and output variables is carried out in the following steps:

Step 1: Determination of the numerical values (1 to 10) of the input parameters (SQKI and IRR).

The numerical value of SQKI for any category j of dominant factors can be determined from eq.1, while the crisp numerical value of the IRR variable can be determined directly from the fuzzy set description for a given or calculated IRR value.

Step 2: Fuzzification of the input parameters to obtain membership degrees ( 0 to 1 ) for the appropriate input fuzzy set.

In this study, the SQKI and IRR crisp numerical values have been fuzzified for each activated rule to yield fuzzy membership degrees for the qualifying linguistic set.

\section{Step 3: Application of fuzzy AND or OR operator in the antecedent (of an activated rule) with more than one membership degree value.}

The application of the AND or OR operator in such antecedents, has resulted in a single truth membership de- gree value representative of the antecedent of that rule. The truth value of an activated rule $r$ is given as [23]:

$$
\text { Or } \left.\begin{array}{c}
\mu_{r}=\operatorname{Min}\left(\mu_{I R R}, \mu_{P S K I}\right) \\
\mu_{r}=\operatorname{Max}\left(\mu_{I R R}, \mu_{P S K I}\right)
\end{array}\right\}
$$

where

Min indicates using the $A N D$ operator to combine two or more membership values of a rule's antecedent.

Max indicates using the $O R$ operator to combine two or more membership values of a rule's antecedent.

$\mu_{I R R}$ is the membership value of the first input parameter IRR for the rth rule

$\mu_{P S K L}$ is the membership value of the second input parameter $S Q K I$ for the $r$ th rule

Step 4: Determination of the consequent fuzzy set for the truth value of each antecedent of the activated rules in the rule base by referring to a database of statistical data, analysed information, concept mapping and expert judgement.

A consequent is the output part of the fuzzy rule $r$ that connects the antecedent. It is represented by a membership function $\mu_{r^{*}}$ Having determined the truth membership value of the antecedent for a rule $r$ in the previous step, a reviewed consequent should be developed to appropriately match this truth value. This matching process involves the use of a function associated with the antecedent to reshape the initial consequent. The input for the consequent modification process is the truth value of the antecedent while the output is a consequent fuzzy set produced by either using the Minimum (Min) AND or Product AND method. The Min AND method truncates the output fuzzy set while the Product AND method scales the output fuzzy set.

In this study, the expression used to generate the membership value of the reshaped WPS consequent for the $r$ th rule has been given as [23]:

$$
\mu(B s: s=1,2,3,4)_{r}=\mu_{r}
$$

where

$B s$ is the output WPS fuzzy set that defines the status of the wharf. $1=$ Red status, $2=$ Orange status, $3=$ Yellow status, 4 = Green status.

Step 5: Aggregation of the consequent fuzzy set across the activated rules into a single fuzzy set for each WPS output variable.

In this study, the result of the aggregation process is a single fuzzy set for each WPS output variable i.e. each variable Red, Orange, Yellow and Green has a single fuzzy set consisting of aggregated consequent values of all the activated rules. The maximum method is used in the aggregation process. The order in which the rules are combined for each output variable is not given any special consideration. The single WPS fuzzy set from the aggregation process can be expressed as [23]: 


$$
\begin{aligned}
(W P S)_{s f s}= & \left\{\operatorname{Max}\left(C_{1 r}, \text { Red }\right) ; \operatorname{Max}\left(C_{2,} \text { Orange }\right) ;\right. \\
& \left.\operatorname{Max}\left(C_{3 r} \text { Yellow }\right) ; \operatorname{Max}\left(C_{4 r} \text { Green }\right)\right\}
\end{aligned}
$$

where

$\mathrm{C}_{1 \mathrm{r}}=$ Consequent membership value of the activated rule

in the first WPS output variable

$\mathrm{C}_{2 \mathrm{r}}=$ Consequent membership value of the activated rule in the second WPS output variable

$\mathrm{C}_{3 \mathrm{r}}=$ Consequent membership value of the activated rule in the third WPS output variable

$\mathrm{C}_{4 \mathrm{r}}=$ Consequent membership value of the activated rule in the fourth WPS output variable

\section{Step 6: Transformation of the output WPS fuzzy set composed of a range of values into a single crisp output value.}

This defuzzification of the output WPS fuzzy set takes away the fuzziness of the output values from the previous step by locating a single value in the output WPS space that appropriately represents all the values in the output WPS fuzzy set for the given crisp input truth value of the antecedent. This single output value could be taken as the mean of the values of the output WPS fuzzy set. However, it can be observed that the generated WPS set is composed in such a way that each output variable is associated with a degree of membership. The generation of a single crisp output value from the various pairs of the output variable values and their associated membership value, will require the application of the centre average defuzzifier method. The single output WPS crisp value can be expressed as:

$(W P S)_{j c r i s p}=\frac{V_{\mathbf{1}} C_{\mathbf{1} r}+V_{\mathbf{2}} C_{\mathbf{2} r}+\cdots+V_{n} C_{n r}}{C_{\mathbf{1} r}+C_{\mathbf{2} r}+\cdots C_{n r}}$

where

$(W P S)_{j c r i s p}=$ Contribution of category $\mathrm{j}$ service quality on the overall performance status of the wharf

$\mathrm{V}_{\mathrm{n}}=$ the value of a given WPS variable i.e. $\mathrm{n}$ could be the

values of Red, Orange, Yellow or Green.

$\mathrm{V}_{1}=$ the value of the first WPS variable

$\mathrm{V}_{2}=$ the value of the second WPS variable

$\mathrm{C}_{\mathrm{n}}=$ the Consequent membership value of the nth WPS output fuzzy set

$j=$ the category of the SQKI influencing the status of the wharf.

\section{Step 7: Determination of the value of overall perform- ance status of the wharf}

Having determined the crisp output WPS values and the weights for the respective categories of the service quality related attributes of the wharf, the value of the overall status of the wharf can be determined using the following relation:

$$
(W P S)_{o v e r a l l}=\sum_{j}^{Z}(W P S)_{j c r i s p} \times(I w)_{j}
$$

where

$(W P S)_{\text {overall }}=$ Overall performance status of the wharf

$(I w)_{j}=$ the importance weight of SQKI service quality category $j$.

\section{Test Case}

The validity of the presented model has been tested to determine the performance status of the Yenagoa wharf, Nigeria. A survey conducted at the jetty revealed that:

Almarine Passport 19 is the standard boat used to carry passengers from the wharf. During festive periods, there is hike in transport fare, passengers pay high amount to reach their destination while the operators make huge profits ensuring that annual return on investment is at least $78 \%$. Owing to the increased number of passengers at the wharf, passengers spend a lot of time at the boarding lounge to board open boats (with available tarpaulin for protection against weather) which is usually overloaded.

The boats whose hull and engine condition are usually good are operating through the busy and mild sea state waterways at high speed under mild weather conditions experienced during this period. Boat operators at the wharf are considered very friendly and very competent. Passengers are provided with some good quality life jacket with a measure of the supervision by regulators whose policies are deemed acceptable for the good of the industry but still need improvements to help clean up the highly debris infested waterways.

\subsection{Determination of the Boat Design and Operations Service Quality Contribution to the Status of the Ferry Service}

Boat design and operations service quality contribution to the status of the ferry service can be seen from subsections 3.2.1 to 3.2.6.

\subsubsection{Determination of the value of the DO-SQKI and IRR Input Variable}

The values of the stakeholders' opinion about each factor are first determined from the fuzzy SQO set definitions in Tables 1, 2 and 3 and the importance weight of each dominant factor (DFW) is taken from Table 4.

For the DO, the SQO of the dominant factors in the fuzzy environment are:

- Cost of Transport Fare, factor $\mathbf{a}=$ high $=2.5$,

- Engine and Hull Condition, factor $\mathbf{b}=\operatorname{good}=5$,

- Boat Speed, factor $\mathbf{c}=$ high $=7.5$,

- Boat Loaded Condition, factor $\mathbf{d}=$ overloaded $=0$ and

- Time Spent at Boarding lounge, factor $\mathbf{e}=\mathrm{a}$ lot $=2.5$

The DFW for factor $\mathbf{a}=0.30$, factor $\mathbf{b}=0.24$, factor $\mathbf{c}=0.18$, factor $\mathbf{d}=0.17$ and factor $\mathbf{e}=0.11$

The DO-SQKI $=(2.5 \times 0.30)+(5 \times 0.24)+(7.5 \times 0.18)+$ $(0 \times 0.17)+(2.5 \times 0.11)=3.57$ 
The DO-SQKI service quality input is 3.57 in the range between low and moderate SQKI fuzzy set shown in Fig.1 while the IRR input value from the test scenario is $75 \%$.

\subsubsection{Fuzzification of the Input Parameters}

The IRR and DO-SQKI input values of $75 \%$ (i.e. IRR of 8.8) and 3.57 respectively are fuzzified over all the qualifying membership functions required by the rule. The following rules that contribute to the evaluation process have been activated:

- Rule \#17: IF the IRR is high AND SQKI is low THEN the WPS is orange

- Rule \#18: IF the IRR is high AND SQKI is moderate THEN the WPS is yellow

- Rule \#22: IF the IRR is very high AND SQKI is low THEN the WPS is red

- Rule \#23: IF the IRR is very high AND SQKI is moderate THEN the WPS is yellow

The fuzzification process is described below:

For rule \#17: IRR at 8.8 corresponding to $\mu_{\text {IRR }}=0.45$ for the high membership function; SQKI at 3.57 corresponding to $\mu_{\text {SOKI }}=0.7$ for the low membership function

For rule \#18: IRR at 8.8 corresponding to $\mu_{\text {IRR }}=0.45$ for the high membership function; SQKI at 3.57 corresponding to $\mu_{\mathrm{SQKI}}=0.55$ for the moderate membership function.

For rule \#22: IRR at 8.8 corresponding to $\mu_{\mathrm{IRR}}=0.85$ for the very high membership function; SQKI at 3.57 corresponding to $\mu_{\mathrm{SQKI}}=0.7$ for the low membership function.

For rule \#23: IRR at 8.8 corresponding to $\mu_{\mathrm{IRR}}=0.85$ for the very high membership function; SQKI at 3.57 corresponding to $\mu_{\mathrm{SQKI}}=0.55$ for the moderate membership function.

\subsubsection{Application of the Fuzzy AND Operator in the} Antecedent of Activated Rules

For rule \#17, the antecedent (IRR is high and the SQKI is low) will yield fuzzy membership values $\left(\mu_{\text {IRR' }}, \mu_{\text {SOKI }}\right)=$ $(0.45,0.7)$ respectively. The minimum of the two values $(0.45)$ is selected on applying the fuzzy AND operator in equation (2). Table 9 below shows the minimum values of the antecedents of the following rules:

Table 9 Truth Membership Values of Antecedents

\begin{tabular}{|l|c|c|c|}
\hline $\begin{array}{c}\text { Activated } \\
\text { Rule }\end{array}$ & $\begin{array}{c}\text { Membership } \\
\text { values of } \\
\text { antecedent 1 } \\
\text { (IRR), } \boldsymbol{\mu}_{\text {IRR,r }}\end{array}$ & $\begin{array}{c}\text { Membership } \\
\text { value } \\
\text { of antecedent 2 } \\
\text { (SQKI), } \boldsymbol{\mu}_{\text {SQKI,r }}\end{array}$ & $\begin{array}{c}\text { Fuzzy AND } \\
\text { operator } \\
\text { (Min), } \boldsymbol{\mu}_{\mathrm{r}}\end{array}$ \\
\hline Rule \#17 & 0.45 & 0.7 & 0.45 \\
\hline Rule \#18 & 0.45 & 0.55 & 0.45 \\
\hline Rule \#22 & 0.85 & 0.7 & 0.7 \\
\hline Rule \#23 & 0.85 & 0.55 & 0.55 \\
\hline
\end{tabular}

\subsubsection{Determination of the Consequent Fuzzy Set for the} Truth Value of Each Antecedent

The consequent WPS fuzzy membership value for rule \#17 with WPS expression orange is given by equation 3 as $\mu\left(B_{2} \text { : orange }\right)_{17}=\mu_{20}=0.45$. Using equation 3 , the consequent WPS fuzzy set for the single truth membership value for all four activated rules are generated as shown below:

Table 10 Consequent WPS Fuzzy Set

\begin{tabular}{|c|c|c|}
\hline $\begin{array}{c}\text { Activated } \\
\text { Rule }\end{array}$ & $\begin{array}{c}\text { Consequence } \\
\text { (WPS expression) }\end{array}$ & $\begin{array}{c}\text { Membership value } \\
\text { of WPS, } \boldsymbol{\mu}_{\mathbf{r}}\end{array}$ \\
\hline Rule \#17 & Orange & 0.45 \\
\hline Rule \#18 & Yellow & 0.45 \\
\hline Rule \#22 & Red & 0.7 \\
\hline Rule \#23 & Yellow & 0.55 \\
\hline
\end{tabular}

\subsubsection{Aggregation of the Consequent Fuzzy Set across the} Activated Rules

The WPS consequent fuzzy set derived are aggregated into a single fuzzy set using equation 4 as shown below:

$$
\begin{aligned}
(W P S)_{D O-S Q K I}= & \{\operatorname{Max}(0,0,0.7,0, \text { Red }) ; \\
& M a x(0.45,0,0,0, \text { Orange }) ; \\
& \operatorname{Max}(0,0.45,0,0.55, \text { Yellow }) ; \\
& \operatorname{Max}(0,0,0,0, \text { Green })\}
\end{aligned}
$$

Therefore, $(W P S)_{D O-S O K I}=\{\operatorname{Max}(0.7, \operatorname{Red}) ; \operatorname{Max}(0.45$, Orange $)$; $\operatorname{Max}(0.55$, Yellow); $\operatorname{Max}(0$, Green $)\}$

The WPS output can be described as Red with a degree of 0.7 , Orange with a degree of 0.45 and Yellow with a degree of 0.55 .

\subsubsection{Defuzzification of the Output WPS Fuzzy Set}

As can be observed from the output WPS fuzzy set, there is a need to have a crisp value that describes the output WPS. The defuzzification of the output WPS fuzzy set derived above is carried out using equation 5 :

$$
\begin{aligned}
& (W P S)_{D O-S Q K I \text { crisp }}= \\
& =\frac{2 \times 0.7+5 \times 0.45+8 \times 0.55}{0.7+0.45+0.55}=1.0
\end{aligned}
$$

The crisp value of the DO-SQKI related WPS of 1.0. It can be deduced that the Design and Operation related WPS estimation reveals that the status of the Wharf is Red with $100 \%$ certainty of its measurement. This result indicates that the boat used at the wharf has major issues and the mode of the boat operation at the wharf is very unsatisfactory to stakeholders. As such, a very drastic corrective action is urgently needed in the design and operational considerations of the boats used at that wharf to forestall catastrophic situations from occurring. 


\subsection{Determination of the Care of Passengers, Safety and Security Service Quality Contribution to the Status of the Ferry Service}

The care of passenger, safety and security service quality contribution to the status of the ferry service can be seen from sub-sections 3.2.1 to 3.2.6.

\subsubsection{Determination of the Value of the CSS-SQKI and IRR Input Variables}

The values of the stakeholders' opinion about each factor are first determined from the fuzzy SQKI set definitions in Tables 1, 2 and 3 and the DFW values are determined from Table 4.

The SQO of dominant factors $f, g, h, i$ and $j$ are as respectively: $10,5,5.5,2.5$ and 10.

The DFW for the dominant factors E, F, G and $\mathrm{H}$ are respectively $0.35,0.27,0.21,0.1$ and 0.07 .

The CSS-SQKI $=(10 \times 0.35)+(5 \times 0.27)+(5.5 \times 0.21)+$ $(2.5 \times 0.1)+(10 \times 0.07)=7.0$

A CSS-SQKI input value is 7.0 on the fuzzy SQKI set definitions as shown in Figure 1 and it is in the high region. The IRR input value from the test case is $75 \%$.

\subsubsection{Fuzzification of the Input Parameters}

The IRR and Env-SQKI input values of 75\% (IRR of 8.8) and 7.0 respectively are fuzzified over all the qualifying membership functions required by the rule. The following rules that contribute to the evaluation process have been activated:

- Rule \#19: IF the IRR is high AND SQKI is high THEN the WPS is green

- Rule \#24: IF the IRR is very high AND SQKI is high THEN the WPS is green

The fuzzification process is described below:

For rule \#19: IRR at 8.8 corresponding to $\mu_{\mathrm{IRR}}=0.45$ for the high membership function; SQKI at 7.0 corresponding to $\mu_{\mathrm{SQKI}}=1.0$ for the high membership function.

For rule \#24: IRR at 8.8 corresponding to $\mu_{\text {IRR }}=0.85$ for the very high membership function; SQKI at 7.0 corresponding to $\mu_{\text {sQKI }}=1.0$ for the high membership function.

\subsubsection{Application of the Fuzzy AND Operator in the Antecedent of the Activated Rules}

For rule \#19, the antecedent (IRR is high and the SQKI is high) will yield fuzzy membership values $\left(\mu_{\text {IRR }}, \mu_{\text {SQKI }}\right)=$ $(0.45,1.0)$ respectively. The minimum of the two values $(0.45)$ is selected on applying the fuzzy AND operator in equation (2). For rule \#24, the fuzzy membership values $\left(\mu_{\text {IRR }}, \mu_{\text {SQKI }}\right)=(0.85,1.0)$ respectively and the minimum value of the antecedents is 0.85

\subsubsection{Determination of the Consequent Fuzzy Set for the Truth Value of Each Antecedent}

The consequent WPS fuzzy membership value for rule \#19 with WPS expression green is given by equation 3 as $\mu\left(B_{4} \text { : green }\right)_{19}=\mu_{19}=0.45$ while for $\# 24$, the consequent fuzzy set is $\mu\left(B_{4} \text { : green }\right)_{24}=\mu_{24}=0.85$
3.2.5 Aggregation of the Consequent Fuzzy Set across the Activated Rules

The aggregation of WPS consequent fuzzy using equation (4) yielded green with a degree of 0.85 .

\subsubsection{Defuzzification of the Output WPS Fuzzy Set}

The crisp value that describes the output WPS derived from the defuzzification process using equation (5) is calculated below:

$$
(W P S)_{C S S-S Q K I \text { crisp }}=\frac{7 \times 0.85}{0.85}=7.0
$$

The crisp value of the CSS-SQKI related WPS of 7.0 is used to determine the degree of the WPS estimation from Figure 3. It can be deduced that the care of passengers, safety and security related WPS estimation reveals the status of the wharf as yellow with $100 \%$ certainty of its measurement. This result gives an indication that some actions need to be taken to ensure that the care of passengers and other safety and security issues related to the ferry service receive some measure of attention.

\subsection{Determination of the Environment Related Service Quality Contribution to the Status of the Ferry Service}

The environment related service quality contribution to the status of the ferry service can be seen from sub-sections 3.3.1 to 3.3.6.

\subsubsection{Determination of the Value of the Env-SQKI and IRR Input Variable}

The values of the stakeholders' opinion about each factor are first determined from the fuzzy SQKI set definitions in Tables 1, 2 and 3 and the importance weight of each dominant factor (DFW) is taken from Table 4.

The SQKI of dominant factors $\mathrm{k}, \mathrm{l}, \mathrm{m}$ and $\mathrm{n}$ are as respectively: 7.5, 2.5, 2.5 and 7.5.

The DFW for the dominant factors $\mathrm{k}, \mathrm{l}, \mathrm{l}, \mathrm{m}$ and $\mathrm{n}$ are respectively $0.33,0.31,0.19$ and 0.17

The Env-SQKI $=(7.5 \times 0.33)+(2.5 \times 0.31)+(2.5 \times 0.19)$ $+(7.5 \times 0.17)=5.0$

The Env-SQKI input is 5.0 in the moderate SQKI fuzzy set shown in Fig. 1 while the IRR input value from the test scenario is $75 \%$.

\subsubsection{Fuzzification of the Input Parameters}

The IRR and Env-SQKI input values of 75\% (IRR of 8.8) and 5.0 respectively are fuzzified over all the qualifying membership functions required by the rule. The following rules that contribute to the evaluation process have been activated:

- Rule \#18: IF the IRR is high AND SQKI is moderate THEN the WPS is yellow

- Rule \#23: IF the IRR is very high AND SQKI is moderate THEN the WPS is yellow 
The fuzzification process is described below:

For rule \#18: IRR at 8.8 corresponding to $\mu_{\text {IRR }}=0.45$ for the high membership function; SQKI at 5.0 corresponding to $\mu_{\mathrm{SOKI}}=1.0$ for the moderate membership function.

For rule \#23: IRR at 8.8 corresponding to $\mu_{\text {IRR }}=0.85$ for the very high membership function; SQKI at 5.0 corresponding to $\mu_{\mathrm{SQKI}}=1.0$ for the moderate membership function.

\subsubsection{Application of the Fuzzy AND Operator in the Antecedent of the Activated Rules}

For rule \#18, the antecedent (IRR is high and the SQKI is moderate) will yield fuzzy membership values $\left(\mu_{\mathrm{IRR}}\right.$, $\left.\mu_{\text {SOKI }}\right)=(0.45,1.0)$ respectively. The minimum of the two values $(0.45)$ is selected on applying the fuzzy AND operator in equation (2). For rule \#23, the fuzzy membership values $\left(\mu_{\mathrm{IRR}}, \mu_{\mathrm{SOKI}}\right)=(0.85,1.0)$ respectively and the minimum values of the antecedents is 0.85 .

\subsubsection{Determination of the Consequent Fuzzy Set for the Truth Value of Each Antecedent}

The consequent WPS fuzzy membership value for rule \#18 with WPS expression yellow is given by the equation (3) as $\mu\left(B_{3} \text { : yellow }\right)_{18}=\mu_{18}=0.45$ while for $\# 23$, the consequent fuzzy set is $\mu\left(B_{3} \text { : yellow }\right)_{23}=\mu_{23}=0.85$

\subsubsection{Aggregation of the Consequent Fuzzy Set across the Activated Rules}

The aggregation of WPS consequent fuzzy using eq.4 yielded yellow with a degree of 0.85

\subsubsection{Defuzzification of the Output WPS Fuzzy Set}

The crisp value that describes the output WPS derived from the defuzzification process using equation (5) is calculated as follows:

$$
(W P S)_{\text {Env-SQKIcrisp }}=\frac{8 \times 0.85}{0.85}=8.0
$$

The crisp value of the Env-SQKI related WPS of 8.0 is used to determine the degree of the WPS estimation from Figure 3. It can be deduced that the Environment related WPS estimation reveals the status of the wharf as yellow with $100 \%$ certainty of its measurement. This result gives an indication that some actions need to be taken to ensure that the environment is suitable for ferry activities. Each of the environmental factors should be reassessed to ensure a conducive and sustainable environment for boat operations.

\subsection{Determination of the Qualitative Status Value of the Wharf.}

The value of the overall status of the ferry activities can be determined using equation (6) as follows:

$$
(W P S)_{\text {overall }}=1 \times 0.4+7 \times 0.4+8 \times 0.2=4.8
$$

The crisp value of the overall status of the wharf is 4.8 on the WPS expression scale and it is within the orange region. The orange status of the wharf shows that there is a likely dissatisfaction among stakeholders at the Yenagoa wharf. The wharf needs a good measure of attention in the various service quality categories (especially the boat design and operation category) for it to operate at an optimal level.

\section{Conclusion}

The study has indicated that even though major service quality components of the wharf are high region (the $\mathrm{EnV}=8.0$ and CSS $=7.0$ in this test case), the overall performance status of the industry may not be necessarily high. The fuzzy rule base method has been able to show the components of the wharf's operations and services that need attention. Hence, it can be applied as a good qualitative and quantitative assessment tool to determine the status and assess the operations of wharves offering ferry services. From the result of the test case, the $(W P S)_{\text {overall }}$ was found to be equal to 4.8. This signifies that the performance status of the Yenagoa wharf is in the orange region. There is a bound to the complaints from stakeholders about the operations at the wharf. There is the possibility of the wharf being classified as a failed wharf, if urgent effort is not made to correct the anomaly existing in the various components of the wharf's operations.

\section{References}

[1] Zeglat, D.: An investigation of the relationship between service quality and profitability in the UK budget hotel sector, $\mathrm{PhD}$ Thesis, School of Management, University of Surrey, 2008.

[2] Lee, M.C. and Hwan, I. S.: Relationships among Service Quality, Customer Satisfaction and Profitability in the Taiwanese Banking Industry, International Journal of Management, Vol. 22, pp. 635-648, 2005.

[3] Valarie, A. Z.: Service quality, profitability, and the economic worth of customers: What we know and what we need to learn, Journal of the Academy of Marketing Science, 28:67, 2000.

[4] Vanniarajan, T., Vikkraman, P.: The Relationship Between Service Quality and Profitability: an Empirical Study in Banking Industry, Smart Journal of Business Management Studies, Vol. 2, Issue 2, pp. 16-21, 2006.

[5] Longman Dictionary of contemporary English, Pearson Education Ltd, England, 2003.

[6] www.dictionary.com/ Accessed 24th May, 2016.

[7] Zadeh, L. A.: Fuzzy Set, Information and Control, 8. pp. 338$353,1965$.

[8] Nwaoha, T. C., Yang, Z., Wang, J., Bonsall, S.: Adoption of New Advanced Computational Techniques to Hazards Ranking in LNG Carrier Operations, Ocean Engineering, Vol. 72, No. 1, pp. 31-44, 2013.

[9] Yen, J., Langari, R.: Fuzzy Logic: Intelligence, Control and Information, Prentice Hall Inc., 1999. 
[10] Nwaoha, T. C., Yang, Z., Wang, J., Bonsall, S.: A Fuzzy Genetic Algorithm Approach for Analysing Maintenance Cost of High Risk Liquefied Natural Gas (LNG) Carrier Systems under Uncertainty, Proceedings of IMarEST, Part A: Journal of Marine Engineering and Technology, Vol. 12, No. 2, pp. 57-73, 2013.

[11] Wang, L.X.: A course in fuzzy systems and control, Prentice Hall Inc., 1997.

[12] L.A. Zadeh.: Outline of a new approach to the analysis of complex systems and decision processes. IEEE Transactions on Systems, Man, and Cybernetics, Vol. 3, Issue 1, pp. 28-44, 1973.

[13] Zade, L. A.: The concept of linguistic variables and its application to approximate reasoning I, II, III, Information Science, 1975.

[14] K.J. Schmucker, Fuzzy sets, natural language computations and risk analysis, Rockville, MD: Computer Science Press, 1984.

[15] Pierre, L.: Species Associations: The Kendall Coefficient of Concordance Revisited, American Statistical Association and the International Biometric Society Journal of Agricultural, Biological, and Environmental Statistics, Vol. 10, Issue 2, pp. 226-245, 2005.

[16] Diefenbach, M.A., Weinstein, N.D. O'Reilly, J.: Scales for assessing perceptions of health hazard susceptibility, Health Education Research, Vol. 8, pp. 181-192, 1993.
[17] Okoli, C., Pawloski, S. D.: The Delphi method as a research tool: an example, design considerations and Applications, Information and management, Vol. 42, Issue 1, pp. 15-29, 2004.

[18] Schmidt, R.C.: Managing Delphi surveys using nonparametric statistical techniques, Decision Sciences Vol. 28, Issue 3, pp. 763-774, 1997.

[19] Delbecq, A.L., Van de Ven, A. H., Gustafson, D. H.: Group techniques for program planning: A guide to nominal group and Delphi processes, Scott, Foresman and Company, Glenview, Illinois, 1975.

[20] Nickerson, J.V., Corter, J.E., Yu, L., Zahner, D., Tversky, B., Rho, J.Y.: Matching Mechanisms to Situations through the Wisdom of the Crowd, in Proceedings of the 13th International Conference on Information Systems, Phoenix. 2009.

[21] Tversky B., Zacks, J.M., Morrison, J.B., Hard, B.M.: Talking about events, in E. Pederson, J. Bohnemeyer, R. Tomlin (Editors), Event representation in language and cognition, pp. 216-227, Cambridge: Cambridge University Press, 2010.

[22] Gentner., A.B. Markman.: Defining structural similarity, Journal of Cognitive Science, Vol. 6, pp. 1-20, 2006.

[23] Sii, H. S., Ruxton, T., Wang, J.: A Fuzzy-Logic-Based Approach to Qualitative Safety Modelling for Marine Systems, Reliability Engineering and System Safety, Vol. 73, pp. 19-34, 2001. 